
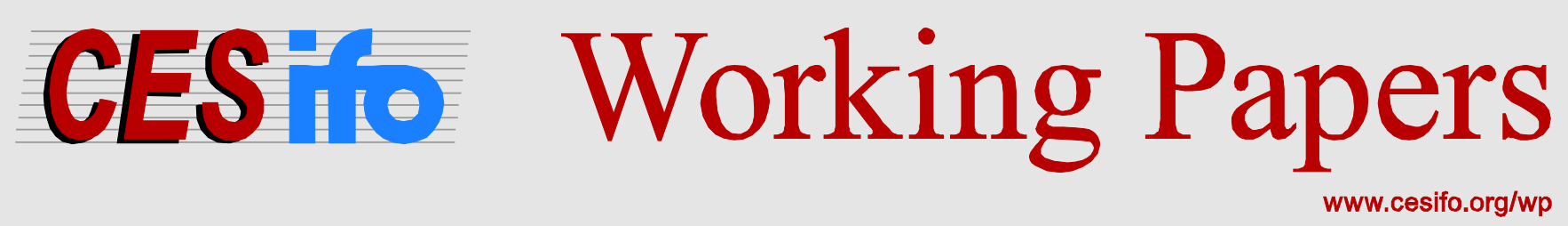

\title{
Market Power in Emission Permit Markets: Theory and Evidence
}

\author{
Beat Hintermann
}

\author{
CESIFO WORKING PAPER NO. 4447 \\ CATEGORY 10: ENERGY AND ClimATE ECONOMICS \\ OCTOBER 2013
}

Presented at CESifo Area Conference on Energy \& Climate Economics, October 2013

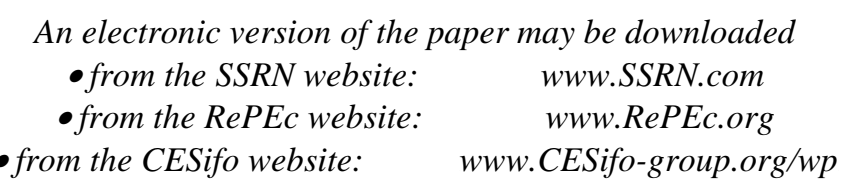




\title{
Market Power in Emission Permit Markets: Theory and Evidence
}

\begin{abstract}
A well-known result about market power in emission permit markets is that efficiency can be achieved by full free allocation to the dominant firm. I show that this result breaks down when taking the interaction between input and output markets into account, even if the firm perceives market power in the permit market alone. In fact, the dominant firm may have an incentive to inflate the permit price even if it receives no free permits at all. I examine the empirical evidence for price manipulation by large electricity firms during Phase I of the EU ETS. I find that the pattern and extent of firms' allowance holdings are consistent with strategic price manipulation, and they appear unlikely to be the result of precautionary purchases due to carbon risk.
\end{abstract}

JEL-Code: H320, Q480, Q530, Q540, Q580.

Keywords: emission permit market, market power, cost pass-through, price manipulation.

Beat Hintermann

University of Basel

Basel / Switzerland

b.hintermann@unibas.ch

October 22, 2013 


\section{Introduction}

Emission permit markets may be susceptible to price manipulation by dominant firms. This topic has been analyzed from a theoretical perspective, starting with the seminal papers by Sinn and Schmoltzi (1981) and Hahn (1984) and extended to a dynamic setting by Liski and Montero $(2005,2011)$. They find that a dominant firm will use its market power to inflate the permit price if it acts as a net seller in the market, and to depress it if it acts as a net buyer. The policy prescription implied by these papers is that in order to achieve efficiency, a dominant firm should be allocated the number of permits it would demand if it were acting as a price taker, thereby removing the firm and (and thus the inefficiency) from the market.

This prescription is unsatisfactory for two reasons. For one, the implication that large firms should bear none of the cost of environmental policy is difficult to justify on equity grounds. More importantly, these results are derived without an interaction between input and output markets. Firms aim to maximize overall profits, not to minimize the compliance costs associated with an environmental regulation; if permit costs influence product markets, the latter have to be taken into account.

Misiolek and Elder (1989) show that if a dominant firm is able to manipulate both the input and output markets, Hahn's prescription of full allocation no longer applies. The dominant firm will generally buy more (or sell fewer) permits than in the case where it focuses on compliance costs alone, as this allows it to increase its market share and overall profits relative to the fringe. Similarly, Sartzetakis (1997) shows that a dominant firm may use emission permits to keep rivals out of the product market.

Disegni Eshel (2005) and Hintermann (2011) shift the focus away from exclusionary manipulation and show that a dominant firm with market power in both the permit and the product market will manipulate both prices so as to increase its profits at the cost of consumers and taxpayers. A dominant net permit buyer may want to increase the permit price, provided that the increase in compliance costs is more than offset by the sum of the revenue increase in the output market and the increase in rents embedded in free allocation. The latter has been discussed under the label of "windfall profits" in the EU ETS: Firms receive a large share of their allocation for free, but nevertheless pass through the opportunity costs of emissions to consumers (Neuhoff et al., 2006; Sijm et al., 2006). This is not a market 
failure, but rather a sign of efficiency: If emissions are capped, permits become a costly input and should therefore be reflected in the marginal cost of production.

In this paper, I show that it is not the presence of "double" market power in the sense that the dominant firm directly influences the price in each market via quantity choices, but rather the reflection of input costs in output prices that leads to a failure of Hahn's prescription of full free allocation. Influencing an input price will affect profits in the output market, and this interconnection is sufficient to generate an incentive for net permit buyers to increase the permit price, provided they receive a sufficient number of permits allocated for free. Restricting market power to one market has the additional benefit that full efficiency can be obtained by allocating the dominant firm a particular number of free permits. This allocation threshold is below the firm's efficient permit demand and necessarily makes it a net permit buyer. If the firm is allocated more (fewer) permits for free, it will use its market power to increase (decrease) the permit price.

The second contribution of the paper is empirical. Although there is a sizable literature about market power in permit markets, the quantitative evidence to date is restricted to laboratory experiments. The size of the distortion from market power depends on the experimental context, but the common finding is that including the output market in the experimental setting and ascribe market power to participants in both markets significantly affects the outcome, relative to the case where the goal is strictly to minimize compliance costs (Brown-Kruse et al., 1995; Godby, 2002; Muller and Mestelman, 1998).

Hintermann (2011) shows that the largest power producers covered by the EU ETS received a permit allocation exceeding the threshold mentioned above, meaning that these firms would have benefited from increasing the permit price despite being net buyers, and I confirm this finding in the current paper for a larger set of firms. Hintermann (2011) proposes price manipulation as a possible reason behind the high price during the first market phase, but he does not provide evidence that market power was in fact exerted.

In this paper, I examine the available data for evidence that large electricity firms inflated the permit price during Phase I. I find that the market is concentrated in the sense that few firms cause most of the emissions, but traditional measures of market power such as the Herfindahl-Hirschman index (HHI) suggest relatively high competition among a few large 
firms, implying that any one firm may not have had much price-setting power. However, the HHI increases when excluding permits allocated to installations that never traded and therefore were effectively not part of the market. For the first and second compliance years, this corresponded to $50 \%$ and $30 \%$ of the emissions cap, respectively.

Direct tests of the theory are not possible, because neither firms' marginal abatement costs nor the "right" permit price (i.e., the one that corresponds to market fundamentals) are known, and reasons other than market power could lead to a deviation between the permit price and marginal abatement costs. I therefore rely on over-purchasing (or equivalently, under-selling by net sellers) of allowances as my measure of market power, which avoids many informational and identification problems.

The reason why I focus on Phase I are twofold: First, I use large firm' excess allowance holdings as a measure of price manipulation, which requires knowledge about allowance transfers. The EU releases this information only with a delay of five years, such that currently allowance transfers are publicly available through the end of 2008. Second, if firms can bank unused allowances to the next phase, the concept of excess allowance holdings loses its meaning because it is simply another word for banking. But because unused allowances were canceled at the end of Phase I, holding more allowances than needed to cover Phase I emissions has to be explained by reasons other than banking. One such reason is over-purchasing (or under-selling) of allowances by large firms in the hope of increasing the allowance price.

I show that some the largest electricity providers covered by the EU ETS held a sizable permit surplus by the end of Phase I, which expired unused due to the no-banking provision. Focusing on allowance holdings after the first two compliance years, I show that the size of the surplus is unlikely to be explained by precautionary purchases to hedge against carbon risk from stochastic emissions in the final year. These results are consistent with strategic purchase decisions implied by the theory. Overall, my results deliver no conclusive proof of price manipulation, as firms' over-purchasing may be explained by reasons other than strategic price manipulation, but they do suggest that market power in permit markets may be of significant policy relevance, and especially so in nascent permit markets where not all firms participate in the market. 


\section{Theory}

In the following I use a simplified version of the model by Hintermann (2011) to show that the threshold of free allocation beyond which a dominant firm will manipulate the price upwards is below full allocation, due to the interaction between input and output markets.

The model consists of a dominant firm (or several colluding firms) and a price-taking fringe. Fringe firms $i \in(2, \ldots, N)$ take output prices $p$ and allowance prices $\sigma$ as given and choose output $q_{i}$, emissions $e_{i}$ and permit holdings $x_{i}$ to maximize profits subject to an emissions constraint:

$$
\max _{q_{i}, e_{i}, x_{i}} \Pi_{i}=p q_{i}-C^{i}\left(q_{i}, e_{i}\right)-\left(x_{i}-\bar{x}_{i}\right) \sigma \quad \text { s. t. } \quad e_{i} \leq x_{i}
$$

Firm $i^{\text {'s }}$ cost function $C^{i}$ depends on both output and emissions and satisfies $C_{q}^{i} \equiv \partial C^{i} / \partial q_{i}>$ 0, $C_{q q}^{i}>0, C_{e}^{i}<0, C_{e e}^{i}>0, C_{q e}^{i}<0$ and $C_{q q}^{i} C_{e e}^{i}-\left(C_{q e}^{i}\right)^{2}>0$. The optimality conditions of this problem are independent of the amount of free allocation $\bar{x}_{i}$ and state that firms equate price with marginal cost in both markets. This means that the fringe firms' optimal output, emissions and permit decisions are a function of market prices:

$$
\begin{aligned}
p & =C_{q}^{i} ; & \sigma & =-C_{e}^{i} \\
\Rightarrow q_{i}^{*} & =q_{i}^{*}(p, \sigma) ; & e_{i}^{*} & =x_{i}^{*}=x_{i}^{*}(p, \sigma)
\end{aligned}
$$

Permit purchase decisions by the dominant firm, which we call firm 1 , have an impact on both the permit and the output price:

$$
\begin{aligned}
& \frac{\partial \sigma}{\partial x_{1}}>0 \\
& \frac{\partial p}{\partial x_{1}}=\frac{\partial p}{\partial Q^{f}} \cdot \frac{\partial Q^{f}}{\partial \sigma} \cdot \frac{\partial \sigma}{\partial x_{1}}>0 ; \quad Q^{f} \equiv \sum_{i=2}^{N} q_{i}
\end{aligned}
$$

A formal proof of (4-5) is provided in Hintermann (2011). Intuitively, the dominant firm's permit purchases affect the permit price directly in (4), and the output price indirectly via the fringe's response: An increase in the permit price lowers the fringe's output, which in turn increases the output price. 
The dominant firm considers (2-5) when maximizing its own profits. An interior solution with $q_{1}, x_{1}, e_{1}>0$ is characterized by the following optimality conditions:

$$
\begin{aligned}
& p=C_{q}^{1} \\
& \sigma+\left(x_{1}-\bar{x}_{1}\right) \frac{\partial \sigma}{\partial x_{1}}-\frac{\partial p}{\partial x_{1}} q_{1}=-C_{e}^{1} \\
& x_{1} \geq e_{1} ; \quad-C_{e}^{1} \geq 0 ; \quad\left(x_{1}-e_{1}\right) \cdot-C_{e}^{1}=0
\end{aligned}
$$

Condition (7) is the core result and shows that the dominant firm will generally not equate the permit price with marginal abatement costs if it receives an allocation equal to its efficient permit demand. The reason is that buying another permit drives up both prices, and both affect the firm's profits. Depending on the free allocation $\bar{x}$ it receives, its influence on the permit price and the effect of the permit price on the output price, the firm sets its marginal abatement costs above or below the permit price. Condition (8) shows further that in the latter case, the dominant firm may not abate at all, and purchase more permits than it needs for compliance. This is the situation I focus on in the empirical part of the paper.

Note that the functional form in (7) and therefore the underlying mechanism is unchanged if we allow for market power in the output market as well. Naturally, the optimal choices of output, emissions and permits will be different, but the insight that the firm's permit purchases affect costs and profits in both markets remains the same.

We can solve (7) for the level of free permit allocation that makes the firm equate its marginal abatement costs to the permit price:

$$
\bar{x}_{1}^{0}=x_{1}-\frac{\partial p / \partial x_{1}}{\partial \sigma / \partial x_{1}} q_{1}<x_{1}
$$

Since both price effects are positive, the efficient solution consists in allocating the dominant firm fewer permits than it needs to cover its emissions as a price taker. ${ }^{1}$ Single-market analysis in the vein of Hahn (1984) or Liski and Montero (2011) do not capture this market interaction

\footnotetext{
${ }^{1}$ Hintermann (2011) also computes a threshold of free allocation that makes the firm act as a price taker in the output market, and shows that this is necessarily smaller than $\bar{x}_{1}^{0}$. The existence of two different thresholds implies that efficiency cannot be obtained by means of free permit allocation alone, which is the familiar result that two market failures require more than one policy instrument for efficiency. Since the assumption here is that the dominant firm perceives market power in the permit market alone, no such threshold exists, and free allocation as defined by (9) is efficient.
} 
effect. Hahn's result of efficiency with full free allocation is a special case and can be derived directly by setting $\partial p / \partial x_{1}=0$.

It can be inferred by comparing (7) with (9) that if the dominant firm is allocated an amount of free permits in excess of $\bar{x}_{1}^{0}$, it will use its market power to inflate the permit price, and vice versa. Because marginal production costs decrease with emissions $\left(C_{q e}<0\right)$, underabatement further implies that the dominant firm increases its market share at the expense of the fringe (its production costs decrease relatively to the fringe). This is consistent with the core result from the literature about raising rivals' costs (Krattenmaker and Salop, 1986; Salop and Scheffman, 1983; Sartzetakis, 1997): A dominant firm has an incentive to increase input costs in order to gain market share at the expense of its rivals, provided that the cost increase hurts it relatively less. If fringe firms equate marginal abatement costs to the permit price but the dominant firm sets $-C_{e}^{1}<\sigma$, an increase in the permit price is relatively less costly for the dominant firm than for the fringe.

Note finally that depending on the level of permit demand and the price effects, the threshold of neutral allocation can be negative. In this case, the dominant firm would have an incentive to inflate the permit price, even if it were to receive no free allocation at all.

\section{Application}

In this section, I focus on the ten largest electricity firms covered by the EU ETS and examine whether they would have found it profitable to inflate the permit price according to condition (9), and if so, whether there is any empirical evidence consistent with permit price inflation during Phase I of the EU ETS . I start with a brief description of the relevant context, before turning to the empirical application.

\subsection{Background}

The European Union Emissions Trading Scheme (EU ETS) is arguably the largest experiment of market-based environmental policy to date. It is a cap-and-trade system that covers $\mathrm{CO}_{2}$ emissions from about 11,000 installations that belong to energy-intensive sectors in all EU countries. It includes around 42 percent of the EU's emissions and served as the EU's primary 
instrument to achieve their Kyoto targets, and it continues to play a dominant role n order to reach the EU's $20 \%$ reduction target by 2020 . The first market "phase" covered the years 2005-2007 and was intended as a trial run for Phase II, which coincided with the Kyoto compliance period 2008-2012. At the time of this writing we are in Phase III, which covers the years 2013-2020.

Apart from their association with different compliance periods defined by international agreements, the phases differ with respect to rules about allocation and banking of emission permits. Whereas permits from Phase I could not be banked into Phase II, because this would have increased emissions beyond the Kyoto targets, there are no limits on banking starting in Phase II. Permit borrowing is allowed within, but not across phases. Permits were allocated mostly for free during Phases I and II, but auctioning is the main method of allocation since Phase III. Importantly, firms in the Power \& Heat sector no longer receive any free allocation. For a more detailed discussion of the institutional setup of the EU ETS, please refer to the technical report by the European Environment Agency (EEA, 2006) and the review by Convery (2009).

Table 1 contains total allocation and emissions by year for the first two market phases, and Figure 1 shows the permit price in the EU ETS during Phases I-II. The price for permits (called EU allowances, or EUAs, giving the holder the right to emit one ton of $\mathrm{CO}_{2}$ ) was above $€ 20$ for much of Phase I, even surpassing $€ 30$ before dropping precipitously when verified emissions were published for the first time in April 2006. The allowance price stabilized around $€ 10-15$ for another half year before approaching zero towards the end of the phase. Similarly, the price rose at the beginning of Phase II, but then declined at the onset of the financial crisis.

Given the no-banking provision between the first two phases, the apparent over-allocation in Phase I should have led to a price close to zero in hindsight. A number of papers have attempted to explain the price behavior. Some have focused on fundamentals such as fuel prices, economic activity and the weather (Hintermann, 2010; Mansanet-Bataller et al., 2007). Others have tried to explain the price path by means of financial theory (Ben; Cetin and Verschuere, 2009; Seifert et al., 2008), or options formulae (Chesney and Taschini, 2012; Hintermann, 2012). In this Section, I examine the empirical evidence for the possibility that 
Figure 1: Allowance spot price in EU ETS, 2005-2012

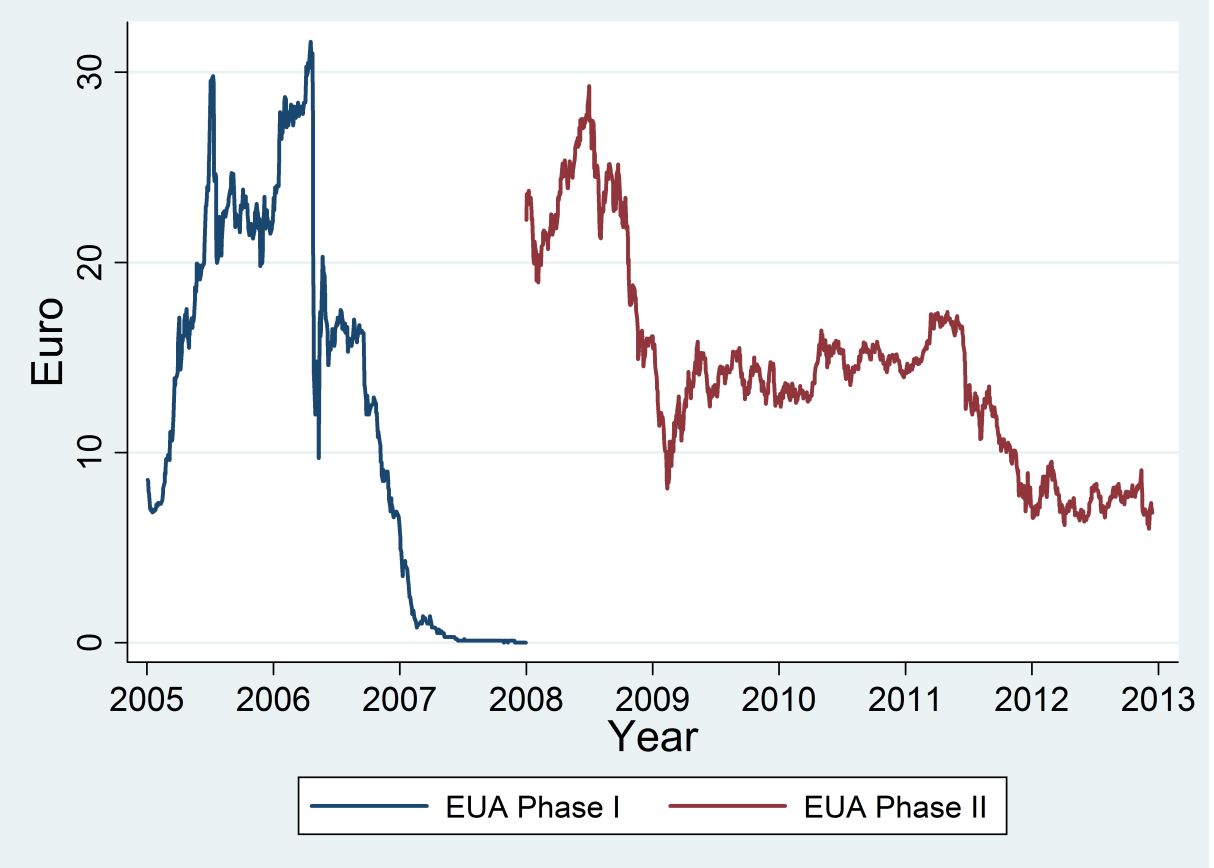

Source: European Energy Exchange.

large firms manipulated the allowance price upwards during the first two years of the phase.

Table 1: Allocation and emissions in EU ETS, 2005-2012

\begin{tabular}{lcccc}
\hline Year & Allocation (Mt) & Emissions (Mt) & Surplus (Mt) & Surplus (\%) \\
\hline 2005 & $2^{\prime} 313$ & $2^{\prime} 014$ & 299 & 12.93 \\
2006 & $2^{\prime} 277$ & $2^{\prime} 036$ & 241 & 10.58 \\
2007 & $2^{\prime} 278$ & $2^{\prime} 165$ & 113 & 4.96 \\
\hline Phase I & $6^{\prime} 868$ & $6^{\prime} 215$ & 653 & 9.51 \\
\hline 2008 & $2^{\prime} 136$ & $2^{\prime} 120$ & 16 & 0.77 \\
2009 & $2^{\prime} 186$ & $1^{\prime} 880$ & 306 & 14.01 \\
2010 & $2^{\prime} 220$ & $1^{\prime} 939$ & 281 & 12.67 \\
2011 & $2^{\prime} 222$ & $1^{\prime} 904$ & 318 & 14.33 \\
2012 & $2^{\prime} 222$ & $1^{\prime} 867$ & 355 & 15.99 \\
\hline Phase II & $10^{\prime} 988$ & $9^{\prime} 710$ & $1 ' 278$ & 11.63 \\
\hline
\end{tabular}

Source: European Union Transaction Log (EUTL).

Figure 2 graphs the firm-level emissions concentration curve (cumulative emissions vs. the cumulative number of firms covered by the EU ETS) during Phase I. ${ }^{2}$ The figure indicates a rather high market concentration, with the bottom $80 \%$ of firms accounting for $3 \%$ emissions, whereas the top $1 \%$ of firms is responsible for $59 \%$.

The largest firms in the EU ETS in terms of emissions are power producers, so if market

\footnotetext{
${ }^{2}$ I performed the aggregation of the installation data in EUTL to the firm level using a dataset produced by J. Jaraite, T. Jong, A. Kazukauskas, A. Zaklan and A. Zeitlberger (at the time of this writing, no official citation method has been suggested). This dataset is based on 2013 ownership information such that I manually adjust any changes based on information given in firms' business reports.
} 
Figure 2: Concentration curve in EU ETS, Phase I emissions

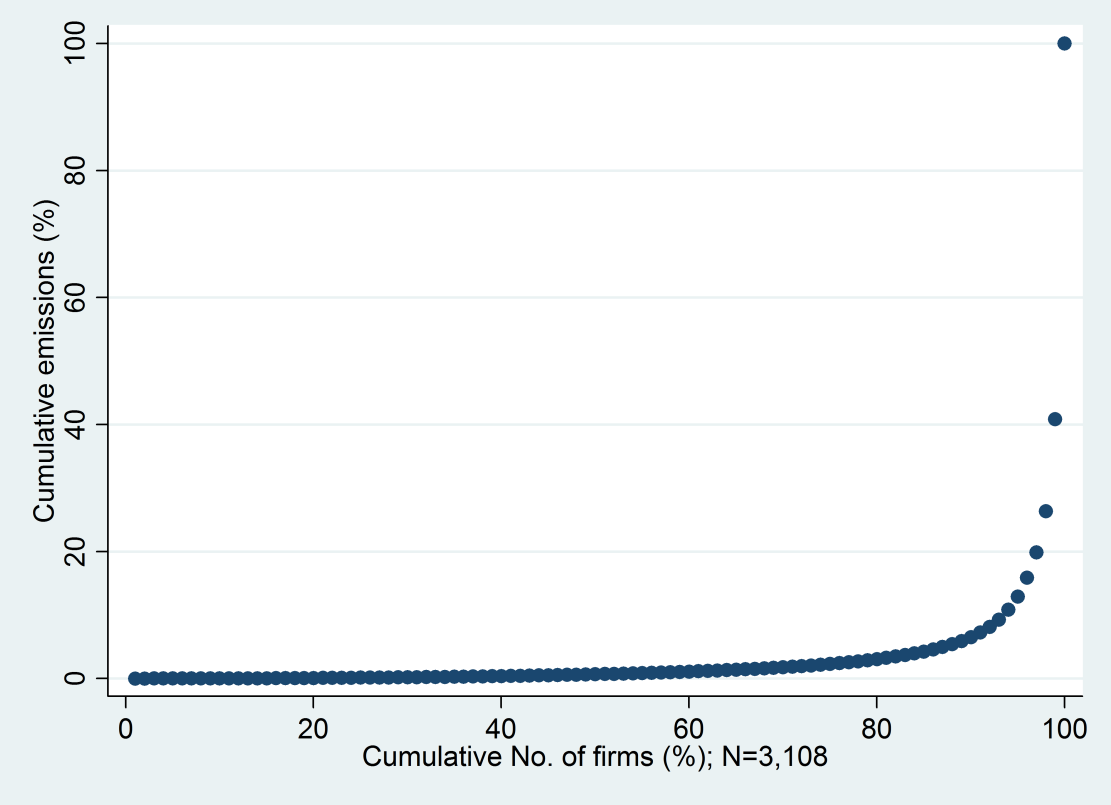

power is an empirically relevant issue, it would arguably arise from the power sector. Figure 3 shows allocation and emissions by sector during Phase I. Because the Power \& Heat sector was the only net buyer in the market, upward price manipulation by electricity generators would be ruled out a priori based on Hahn's (1984) results; however, as I show above, the interaction with the output market qualitatively changes this finding.

Figure 3: Allocation and emissions by sector, Phase I

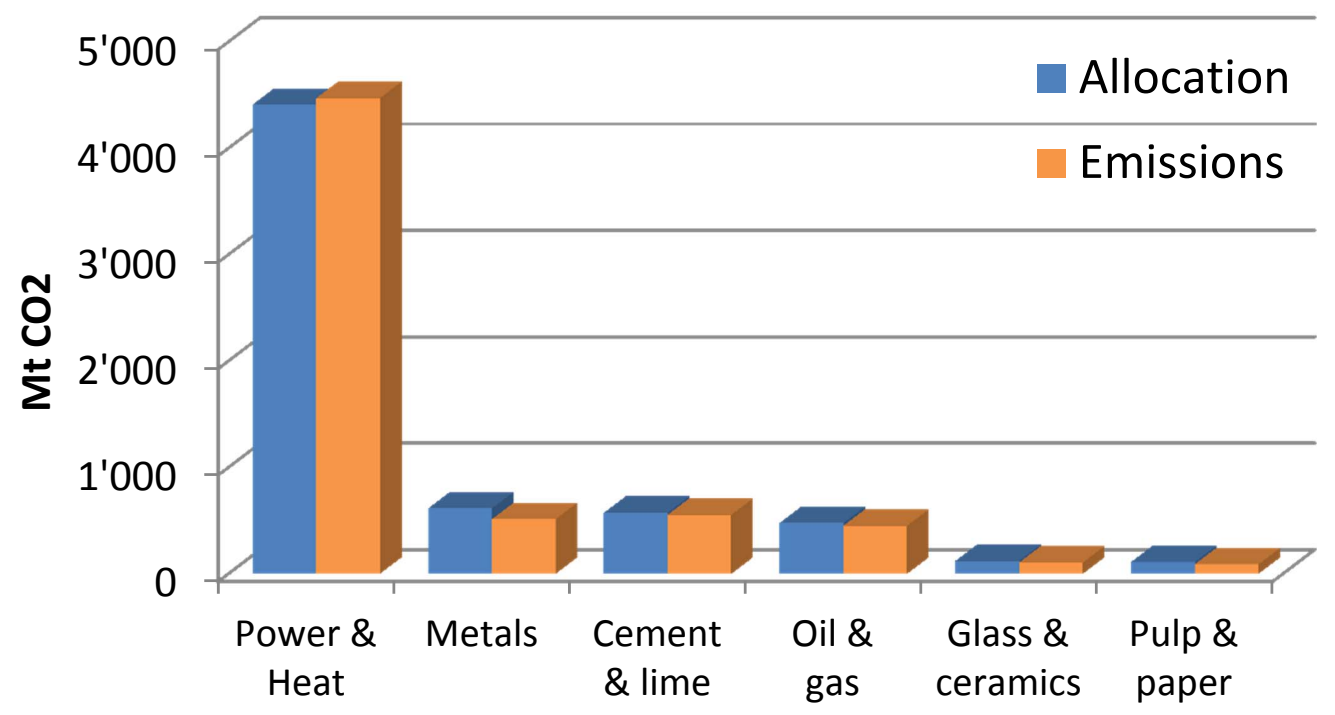

Source: Own illustration based on EUTL data. 


\subsection{Incentives for large electricity firms}

The price responses in the definition of $\bar{x}_{1}^{0}$ are not observed, requiring the choice of an empirical substitute. Totally differentiating the output and permit price and dividing the former by the latter gives

$$
\frac{d p}{d \sigma}=\frac{\partial p / \partial x \cdot d x+\partial p / \partial q \cdot d q}{\partial \sigma / \partial x \cdot d x+\partial \sigma / \partial q \cdot d q}
$$

If both the output and the permit price only depend on the dominant firm's permit purchases as assumed in the theory section such that $\partial p / \partial q=\partial x / \partial q=0$, the allocation threshold simplifies to ${ }^{3}$

$$
\bar{x}_{1}^{0}=x_{1}-\frac{d p}{d \sigma} q_{1}
$$

The ratio $d p / d \sigma$ refers to pass-through of carbon costs to electricity prices. Estimates vary and depend on the method, the market(s) under consideration, assumptions about endogeneity of input and output prices, the load period and also the time frame; for a review and the empirical challenges of estimating cost pass-through, see Fell et al. (2013). I will employ a range of 0.4-0.1 $\mathrm{tCO}_{2} / \mathrm{MWh}$ with a central value of 0.7 , which means that an increase in the allowance price of $1 € / \mathrm{tCO}_{2}$ leads to an average increase in electricity prices by $0.7 € / \mathrm{MWh}{ }^{4}$

Figure 4 contains 2006 generation largest fifteen electricity firms in Europe by type of energy source. For the remainder of the paper I focus on the ten largest of these in terms of output, but I replace British Energy by CEZ because the former has very little fossil capacity and thus relatively few emissions. Table 2 shows generation, emissions, allocation, and the corresponding allocation threshold $\bar{x}^{0}=x-\phi q$ for these ten firms, with $\phi \equiv d p / d \sigma$. All of them received a free allocation in excess of $\bar{x}^{0}$ for the entire range considered for $\phi$, indicating that they profited from an increase in the carbon price, even though most of them were net

\footnotetext{
${ }^{3}$ The output price may depend on the dominant firm's output, even if the firm does not take this relationship into account when deciding on its optimal output and permit purchase decisions. Hintermann (2011) shows that if the dominant firm's output is nondecreasing in $\sigma$ (which will be the case if the demand response is sufficiently small; recall that the dominant firm expands its market share at the cost of the fringe when $\sigma$ increases), it follows that $\frac{d p}{d \sigma}<\frac{\partial p / \partial x_{1}}{\partial \sigma / \partial x_{1}}$ such that (11) $>$ (9).

${ }^{4} \mathrm{To}$ put these numbers into perspective, a combined-cycle gas turbine produces around $0.42 \mathrm{tCO} / \mathrm{MWh}$ of electricity, whereas the emission intensity of a hard coal plant is around $0.96 \mathrm{tCO}_{2} / \mathrm{MWh}$. Therefore, the range of 0.4-1.0 spans the range of full carbon cost pass-through of coal and gas generation.
} 
Figure 4: Generation by energy source of largest electricity firms in Europe

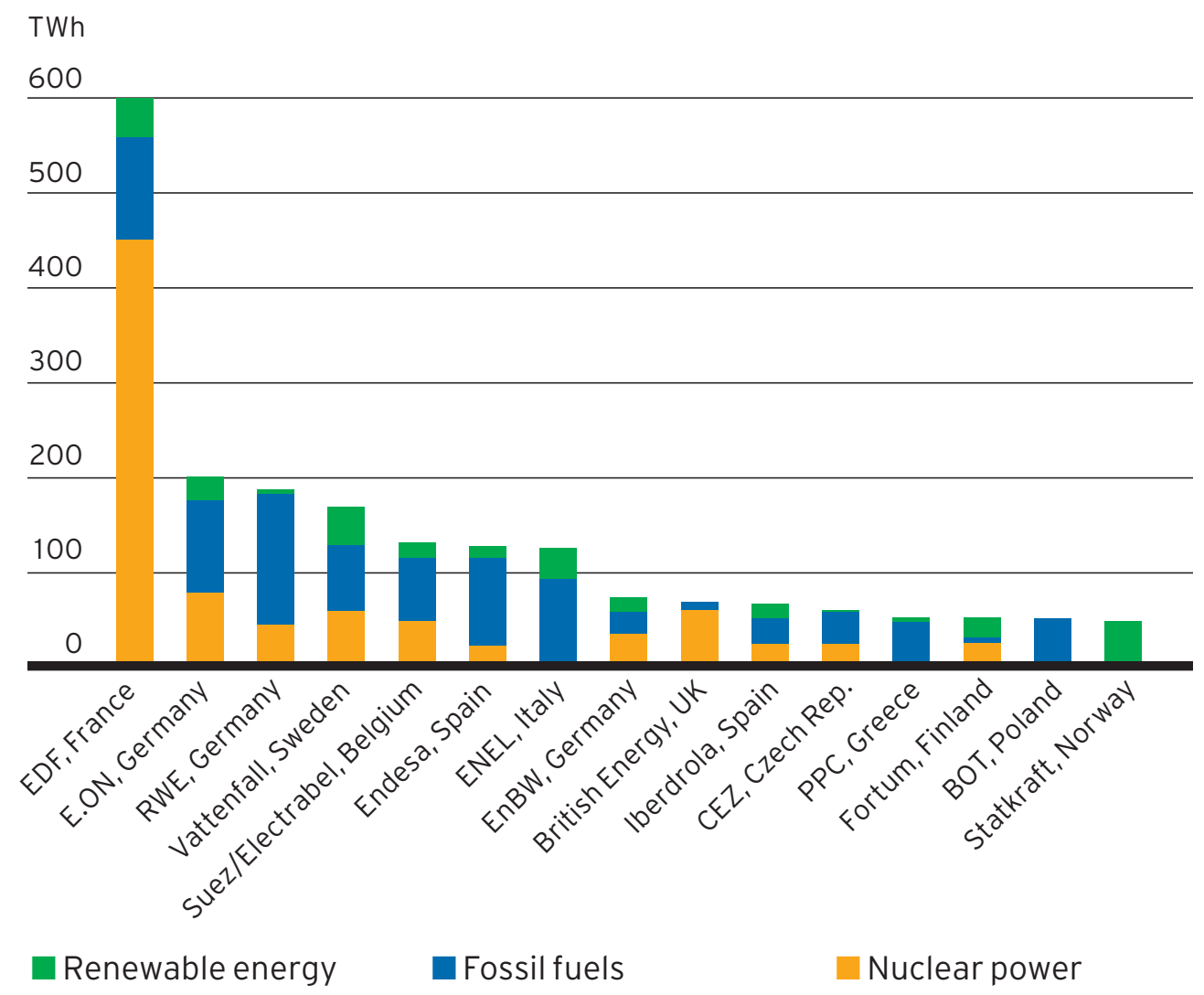

Source: Vattenfall, 2006 business report.

permit buyers. This is consistent with the results by Oberndorfer (2009), who finds a positive correlation between the allowance price and electricity firms' stock performance.

Depending on the value of $\phi$, the threshold of efficient allocation is even negative for some firms, suggesting that they would profit from the introduction of the permit market even under full auctioning. The underlying reason is that most firms generate electricity using a range of sources including nuclear and renewable energy, and thus have an average emission intensity that is below that of the marginal generator. With full pass-through of carbon to electricity prices as implied by the empirical literature, firms with an emission intensity below $\phi$ will profit from a positive carbon price even in the absence of free allocation. ${ }^{5}$ Not surprisingly, the firm with the highest allocation threshold is RWE, which produces a large share of its generation using lignite and coal. Note, finally, that these firms held a combined 33.5 million allowances at the end of the phase as shown in the last column of Table 2, which expired unused due to the no-banking provision.

\footnotetext{
${ }^{5}$ To see this, set $x_{1}=e_{1}$ and $\bar{x}_{1}^{0}=0$ in (11); if a firm's emission intensity $\rho \equiv e_{1} / q_{1}<d p / d \sigma$, it will profit from the introduction of the permit price because it is compensated by consumers on average $d p / d \sigma \cdot \sigma \cdot q$, whereas it only incurs costs of $\rho \cdot \sigma \cdot q$ to cover its emissions.
} 
Table 2: Output, permit holdings and emissions of firms in sample, 2005-2007

\begin{tabular}{|c|c|c|c|c|c|c|c|c|c|c|}
\hline & \multicolumn{2}{|c|}{ Emissions } & \multicolumn{2}{|c|}{ Allocation } & \multicolumn{2}{|c|}{ Generation } & \multicolumn{3}{|c|}{$x^{0}=x-\phi q(M t)$} & \multirow{2}{*}{$\begin{array}{c}\text { Surplus } \\
\text { (Mt) }\end{array}$} \\
\hline & $(\mathrm{Mt})$ & Share & $(\mathrm{Mt})$ & Share & (TWh) & Share & $\phi=0.4$ & $\phi=0.7$ & $\phi=1.0$ & \\
\hline RWE & 443 & $7.1 \%$ & 414 & $6.6 \%$ & 656 & $6.8 \%$ & 200 & 3 & -194 & 19.7 \\
\hline E.ON & 292 & $4.7 \%$ & 257 & $4.1 \%$ & 607 & $6.3 \%$ & 50 & -132 & -314 & 0.2 \\
\hline Vattenfall & 263 & $4.2 \%$ & 272 & $4.3 \%$ & 512 & $5.3 \%$ & 62 & -92 & -246 & 3.4 \\
\hline $\mathrm{EdF}$ & 174 & $2.8 \%$ & 166 & $2.6 \%$ & $1^{\prime} 728$ & $17.8 \%$ & -510 & $-1^{\prime} 029$ & $-1^{\prime} 547$ & 6.8 \\
\hline Suez & 161 & $2.6 \%$ & 146 & $2.3 \%$ & 469 & $4.8 \%$ & -26 & -166 & -307 & 1.4 \\
\hline ENEL & 154 & $2.5 \%$ & 129 & $2.0 \%$ & 310 & $3.2 \%$ & 30 & -63 & -156 & 0.0 \\
\hline Endesa & 136 & $2.2 \%$ & 109 & $1.7 \%$ & 393 & $4.1 \%$ & -21 & -139 & -257 & 0.1 \\
\hline CEZ & 120 & $1.9 \%$ & 127 & $1.3 \%$ & 120 & $1.9 \%$ & 72 & 36 & 0.4 & 0.4 \\
\hline EnBW & 42.8 & $0.7 \%$ & 43.4 & $0.7 \%$ & 222 & $2.3 \%$ & -45 & -111 & -178 & 1.4 \\
\hline Iberdrola & 35.6 & $0.6 \%$ & 25.1 & $0.3 \%$ & 36 & $0.6 \%$ & 22 & 11 & 0.2 & 0.2 \\
\hline Sum & 1'822 & $29.3 \%$ & 1'688 & $26.7 \%$ & 5'053 & $52.2 \%$ & & & & 33.5 \\
\hline
\end{tabular}

Source: Emissions, allocation and permit holding data from EUTL; generation data from business reports.

The included ten firms generate about $52 \%$ of the electricity demanded in the EU and were responsible for $29 \%$ of all emissions in the EU ETS. However, because there are several large firms rather than just one or two, the potential for market power as measured by the Herfindahl-Hirschman index (HHI) is quite low, as shown in Table 3. The US Department of Justice considers markets with an HHI of over 0.15 to be moderately concentrated, and above 0.25 to be highly concentrated (US Department of Justice, 2010), whereas the EU states that there is no concern with firm mergers in a market with a HHI of below 0.1 (European Commission, 2004).

Table 3: Hirschman-Herfindahl Index (HHI)

\begin{tabular}{lcc}
\hline Basis & \% of cap & HHI \\
\hline & & \\
Full cap & 100 & 0.020 \\
Marketed by Apr 2008 & 95.3 & 0.022 \\
Marketed by Apr 2007 & 70.6 & 0.043 \\
Marketed by Apr 2006 & 50.8 & 0.076 \\
& & \\
Marketed by Apr 2007+ collusion & & \\
2 largest firms & 70.6 & 0.061 \\
4 largest firms & 70.6 & 0.111 \\
6 largest firms & 70.6 & 0.166 \\
8 largest firms & 70.6 & 0.218 \\
10 largest firms & 70.6 & 0.237 \\
\hline
\end{tabular}

However, market participation was quite low initially, because many firms first had to become acquainted with the new market. Especially smaller firms, which tended to be over- 
allocated, appeared to be very cautious about the new market and were reluctant to sell their surplus allowances (Jaraite et al., 2010). This lack of liquidity implies that electricity firms may have had the power to influence the permit price by sustained purchases, especially during the initial phase, despite owning a limited share of permits. Defining the share of "marketed" permits as the share of the total cap allocated to installations that traded at least once by a certain date, and assuming that the remainder of the permits are not offered for sale (recall that sectors other than Power and Heat were net permit sellers), the basis upon which the HHI is calculated changes. Whereas most installations traded at some point prior to April 30, 2008 bringing the marketed share to $95 \%$, only about $71 \%$ of the cap was marketed by April 2007, and just over half by April 2006, leading to an HHI of $0.076 .{ }^{6}$ Note that this may still be an underestimate, since it is not clear that a firm that trades once is active in the sense that it observes the price and re-adjusts its permit holdings on a continuous basis, as is implicitly assumed in an efficient market. In general, it is not clear that the HHI is a meaningful measure in a new market where neither demand nor supply is known, and where firms are in the process of learning.

The lower half of Table 3 displays the HHI for various degrees collusion among the top firms in terms of emissions, using the ordering in Table 2. For example, if RWE and E.ON were to collude in their permit purchase decisions, the HHI corresponding to the allocation marketed by April 2007 would increase to 0.061; if all ten firms were to agree on increasing the allowance price, the HHI would reach 0.237 . To be clear, the assumption of collusion is purely hypothetical and serves to give an indication of the degree of collusion required in order for the HHI to reach a level that would be of concern to competition authorities.

\subsection{Evidence for market manipulation based on allowance holdings}

Based on the HHI, we would not conclude that the allowance price in Phase I was subject by price manipulation. However, since the HHI may not reflect the ability of large firms to influence prices in a new market and since it is, in any case, only an indication of market power, I

\footnotetext{
${ }^{6}$ This calculation is based on a subset of countries for which it is possible to match the installation ID between EUTL's "Operator Holding Accounts" and "Transactions" subsections. This subset includes 16 EU countries that together account for $86 \%$ of total allocation: CZ, DE, EE, ES, FI, FR, GB, HU, IT, LT, LU, LV, NL, PL, PT and SE. For the ten firms in our sample, we use actual allowance holdings; for the remaining firms, we do not have the holdings information and therefore assume that holdings=emissions.
} 
now turn to more direct evidence for firm behavior consistent with price manipulation.

The most direct test of the theory developed in Section 2 would be to compare the allowance price with firms' marginal abatement costs. But even if marginal abatement costs were observable, which they are not, there are at least two reasons other than market power that could explain $-C_{e}<\sigma$ : First, firms had reasons to expect that free allocation in Phase II was going to be based on emissions during Phase I, creating a strong disincentive to abate (Bohringer and Lange, 2005; Harstad and Eskeland, 2010): In addition to the cost of abatement, abating another unit of emissions leads to a decrease in the expected future free allocation. As it turned out, Phase II allocation was indeed based on emissions during 2005, despite prior assertions by the EU that it would not to engage in such allocation "updating".

Second, if abatement requires irreversible investment, the uncertainty inherent in future abatement costs leads to a "real option" value of waiting (Dixit and Pindyck, 1994; Zhao, 2003). Firms will only engage in irreversible investment if they are compensated for this loss of flexibility, which means that the allowance price is equal to the purely engineering-based cost of reducing emissions by a ton plus the option value.

To avoid this identification problem, I focus on the case where firms under-abate and over-purchase (or under-sell) permits to the extent that $x_{1}>e_{1}$; i.e., where firms chose to hold more permits than they needed to cover their emissions, and presumably did not abate emissions at all. While updating of free allocation can be expected to have an impact on abatement, it should not lead to over-purchases, as future allocation is based on past emissions, not permit holdings. Likewise, it is not clear how irreversible investment under uncertainty should lead firms to over-purchase allowances to the point where their emissions constraint is not binding. Note that this approach leads to a relatively conservative interpretation of market power: As shown in the theory section, firms may manipulate the price even if their emissions constraint is binding.

Besides the total number of surplus permits, the timing of permit purchases is important. Considering the permit price path shown in Figure 1, we would expect that purchasing permits towards the end of the phase is qualitatively different from purchasing permits in the beginning when prices were too high, at least from an ex-post perspective.

Figure 5 shows a time series of selected firms' cumulative permit surplus, defined as cu- 
mulative allowance holdings minus cumulative emissions as recorded in the EUTL, under the assumption that the annual free allocation and emissions are spread evenly across the year. Although there is no clear pattern, we can make two observations: First, firms seem to have chosen different strategies: Whereas RWE built up a permit surplus early on, other firms held fewer permits than needed to cover their realized emissions in the beginning, building up a surplus later on (EdF, E.ON), or not at all (ENEL). This suggests that collusion among all electricity firms in the permit market is unlikely.

Figure 5: Cumulative allowance surplus of selected firms, Phase I

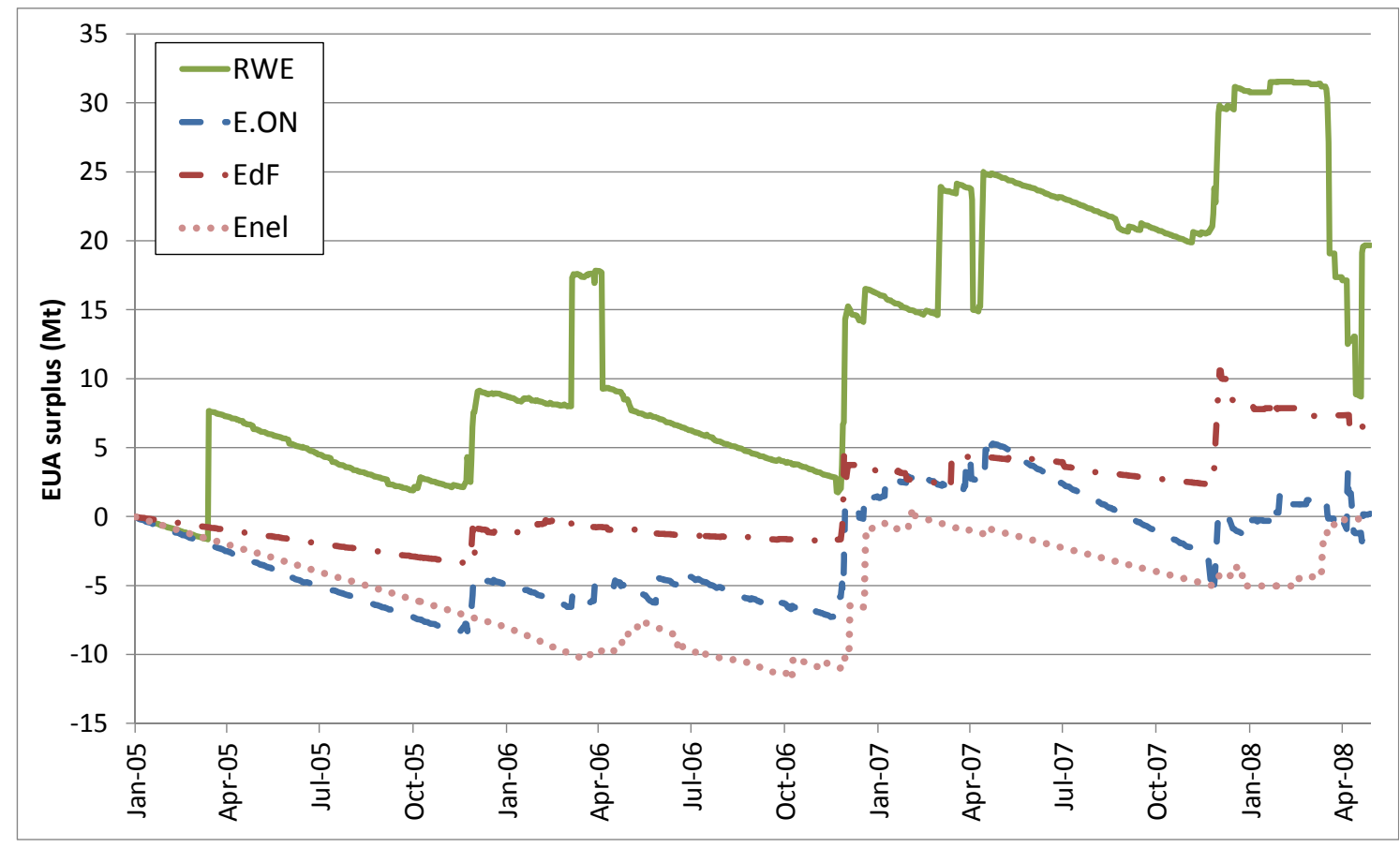

Source: Own illustration based on EUTL data; surplus=allocation + purchases-sales-emissions.

Second, the figure displays a data limitation: We observe actual permit transfers only, whereas an important share of permits are traded via future contracts, meaning that the day of the price signal and the flow of allowances typically do not coincide. This is the reason why the allowance surplus in the registry increases discretely towards the end of the year (December contracts) and in April (when permits have to be surrendered to cover the emissions from the previous year). Note that EUA futures on all exchanges are settled physically. ${ }^{7}$

The separation between the contract and transfer dates renders any intra-year analysis of

\footnotetext{
${ }^{7}$ EUA futures contracts are traded on EEX, ICE and Nasdaq OMX, and until 2012 also on BlueNext. Note that if contracts were settled financially, there could be a price signal that is never followed by a transfer of EUAs. Naturally, there may be bilateral contracts that are settled financially, but such contracts are typically invisible to others and therefore should not affect the market price for EUAs.
} 
the correlation between transfers and price movements moot. To obtain some information about the timing of permit purchases and sales, I therefore focus on annual data, or more specifically, on data organized by "compliance year", which I define until the 30th of April of the following year because that is the date by which firms have to surrender allowances to cover the preceding calendar year. Therefore, compliance year 2005 defines the period from January 1, 2005 to April 30, 2006; compliance year 2006 covers from May 1, 2006 through April 30, 2007; and compliance year 2007 covers May 1, 2007 through April 30, 2008. Figure 6 shows firms' cumulative permit surplus by compliance year defined this way, sorted by the cumulative surplus at the end of compliance year 2007. Because firms received their free allocation in January of each year, a negative surplus is possible for 2005 and 2006 and means that a firm engages in within-phases borrowing. The final surplus is given by the CY 2007 bar and corresponds to the last column in Table 2. The annual representation permits a somewhat clearer view of firms' strategies. Whereas only RWE and CEZ had an allowance surplus at the end of the first compliance year, eight firms built up a surplus by the end of the second compliance year.

Figure 6: Cumulative allowance surplus by compliance year (CY; ordered by CY 2006)

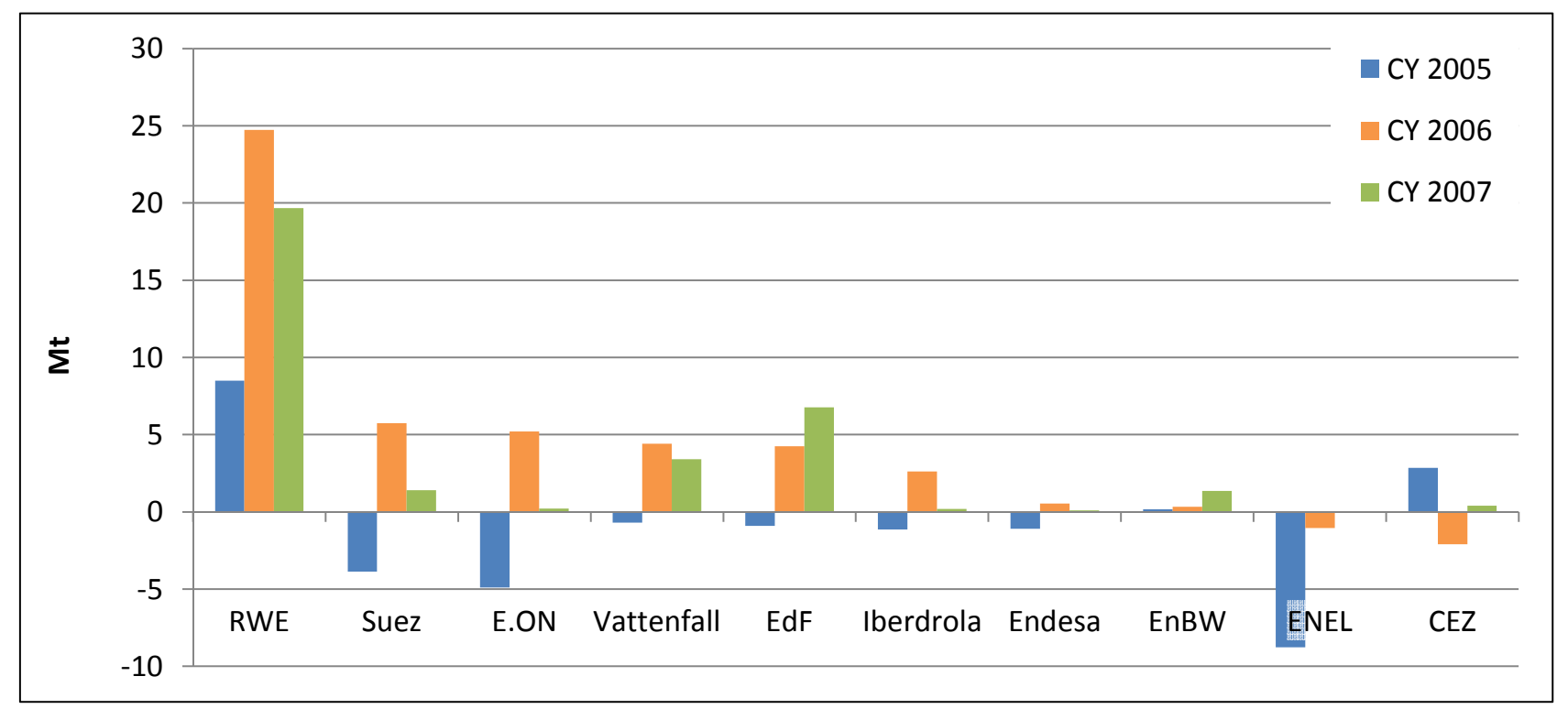

Other than a sign of strategic over-purchasing in order to manipulate the allowance price upwards, a positive surplus could be explained by hedging against future carbon risk. Since emissions depend on generation and the fuel mix, which in turn depend on consumer demand and fuel prices that are uncertain, firms do not know with certainty what their future emis- 
sions will be. Holding surplus permits can then be viewed as a method of hedging against the risk of having to pay a penalty in case the cap turns out to be binding (Chesney and Taschini, 2012; Hintermann, 2012).

If firms hedge against price risk by selling their output and purchasing their inputs on forward markets, holding an allowance surplus in April 2007 would make sense up to the extent of the uncertainty embedded in future emissions. Figure 7 shows firms' surplus after compliance year 2006 relative to the realized 2007 emission. The left bar displays the gross surplus, indicating that six firms held surplus allowances exceeding five percent of their emissions until the end of the phase, and three had an excess of more than ten percent.

Figure 7: Surplus in April 2007, relative to 2007 emissions

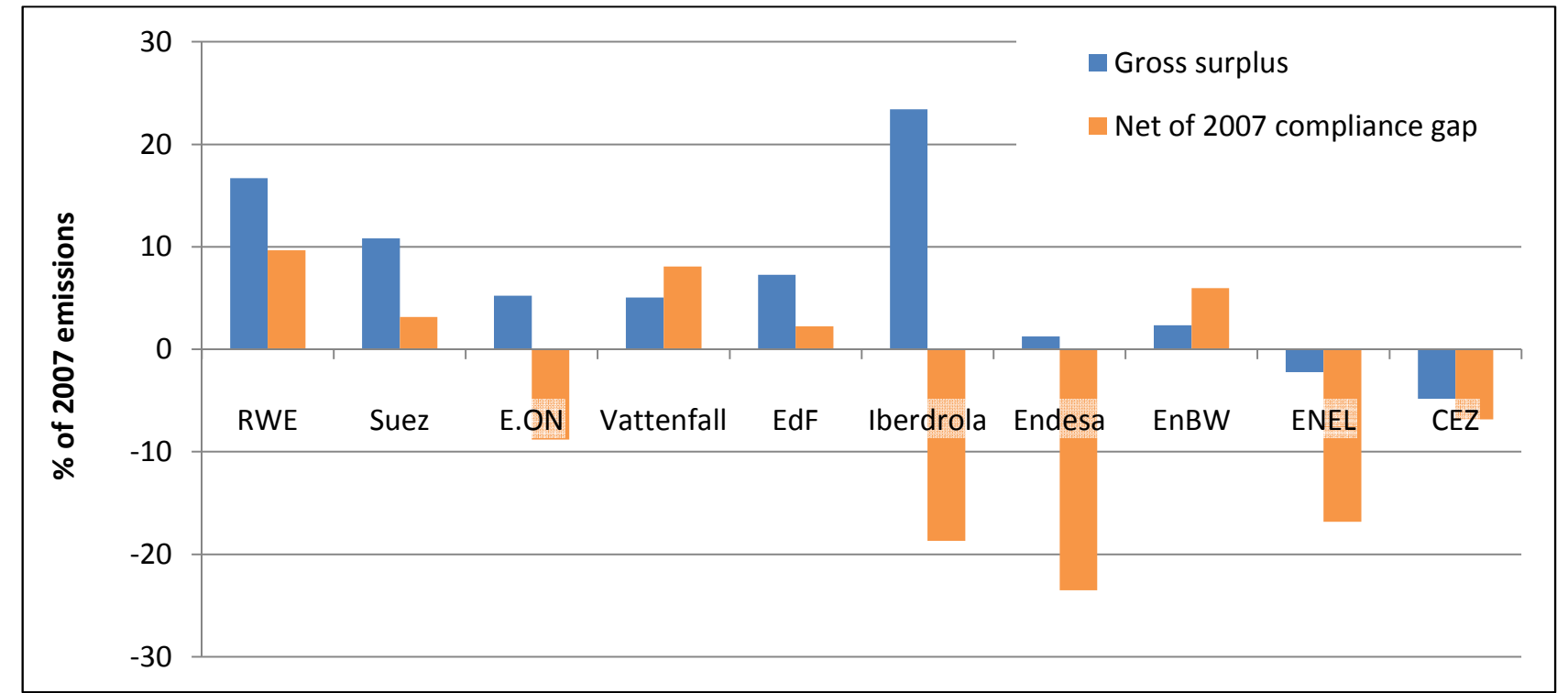

It is possible that firms do not balance their expected allowance holdings on forward markets, but instead make sure that they have a sufficient number of allowances to cover their emissions for the remainder of the phase without further access to the market (this implies a rather high level of carbon risk aversion). The right bars in Figure 7 show the surplus in compliance year 2006 net of the expected compliance gap in 2007 (expected 2007 emissions minus the free allocation received in January of the same year), again relative to 2007 emissions. This measure is smaller than the gross surplus for net buyers, and larger for net sellers. The figure shows that five firms held more permits than needed to cover their emissions until the end of the phase without any further purchases, with the maximum held by RWE who had a net surplus corresponding to about $10 \%$ of its 2007 emissions. 
To put this into perspective, I engage in an exercise of "uninformed prediction". Using information that is publicly available, I create a forecast of fossil fuel generation for RWE, E.ON and Vattenfall using quarterly output data (ideally, this exercise would be done based on emissions rather than output, but emissions are not available on a quarterly level). Specifically, I predict fossil generation during quarters 2-4 based on information available by the end of quarter 1, which includes output in the first quarter, spot electricity prices, as well as electricity futures for the next 1-3 quarters. I further include the FTSE index for Germany and quarterly dummies in the regression. Figure 8 shows actual and predicted quarterly output for the years 2003-2012 for these three firms, with the "prediction" for the first quarter coinciding with actual output by construction. ${ }^{8}$ On average, the absolute average prediction of annual output deviates from actual output by between 2.1\% (RWE) and $3.9 \%$ (Vattenfall), with the standard deviation ranging from $1.7 \%$ (RWE) to $2.8 \%$ (E.ON). The maximum positive deviation is $4.0 \%$ for RWE, $5.0 \%$ for E.ON and $7.1 \%$ for Vattenfall.

Figure 8: Actual and predicted fossil generation for selected firms, 2003-2012

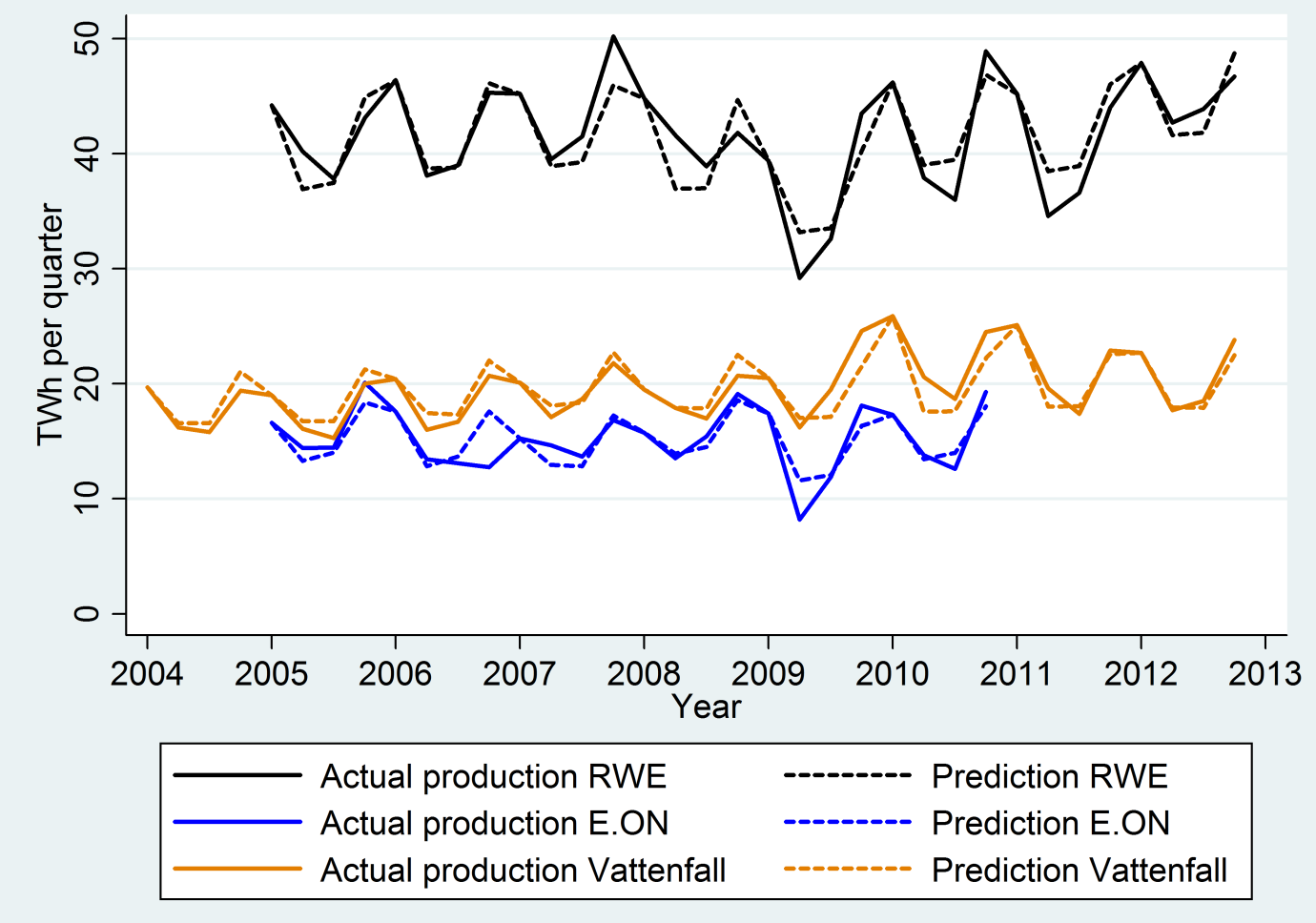

${ }^{8}$ The actual regression output is not shown but available upon request. I regress output on the corresponding monthly prices in January, February and March (i.e., for Q2, this is the one-quarter future, for Q3 the two-quarter future, etc.), along with January, February and March values of the FTSE, quarterly dummies and a constant. I estimate this equation using OLS, form the predictions, and replace the predictions with actual output for quarter 1. I chose these three firms because they are the largest firms in the sample for which I was able to find generation by quarter and energy source. 
Arguably, electricity firms can produce more accurate predictions of their output and corresponding emissions for the next nine months, based on detailed load forecasts and information about planned maintenance operations in their generation portfolio. The increase in solar and wind generation capacity in recent years has made it more difficult to predict fossil generation due to intermittency, but the share of solar and wind generation in 2005-2007 was in the single-digit percentage range. ${ }^{9}$ It therefore seems difficult to reconcile the allowance surplus shares in Figure 7 by hedging against carbon risk at least for some firms, or to put it differently, the observed allowance surplus would appear to be an unusually conservative and costly hedge against a moderate risk.

\section{Conclusions}

Because firms aim to maximize overall profits rather than minimize emission compliance costs, the interaction between the emission and output markets is crucial for understanding the conditions under which a dominant firm will use its market power to increase or decrease the permit price. I show that even net permit buyers can have an incentive to inflate the permit price by over-purchasing permits and under-abating emissions, whereas net sellers would under-sell. If a firm's average emission intensity is below the average emission intensity of the marginal generator and carbon costs are fully passed through, the firm has an incentive to inflate the permit price, even if it receives no free allocation at all.

I derive these results under the assumption of "single" market power in the sense that the dominant firm ignores the effect of its output quantity decision on the product price. These results are therefore a special case of the results in Hintermann (2011), but they highlight the insight that it is not the simultaneous manipulation of two markets that leads to this qualitative departure from Hahn's (1984) prescription of full allocation, but the simple fact that emission permits are a necessary input of production and therefore are reflected in the output price. Using data about permit holdings and output during Phase I, and applying a broad range of carbon cost pass-through, I show that the largest ten electricity firms covered by the EU ETS would indeed have profited from increasing the permit price during the first

\footnotetext{
${ }^{9}$ According to the ENTSO-E historical database, $5.6 \%$ of total generation in Germany was due to wind in 2005-2007; during that period, ENTSO-E did not yet list generation by solar.
} 
phase of the market, even though seven of these firms were net permit buyers.

Naturally, having an incentive to increase the allowance price and actually doing it are two different things. The EU ETS is concentrated in the sense that a few firms account for a large share of overall emissions, and the top $1 \%$ is responsible for close to $60 \%$ of emissions. On the other hand, market concentration based on the Herfindahl index is rather low, because there are several and not just one large firm. The HHI increases when excluding allowances held by installations that never traded, and by assuming collusion. However, the HHI may not be a useful measure for a new market where many small firms adopted a waitand-see approach whereas the large electricity firms purchased allowances at a steady rate from the beginning, and I therefore examine more direct evidence for price manipulation. My empirical strategy consists in focusing on excess allowance holdings as a potential sign of price manipulation, which should avoid identification issues relating to allocation "updating" and investment under uncertainty, and which also does not require assumptions about firms' abatement technology.

I show that several of the largest electricity firms accumulated a sizable allowance surplus by April 2007. The permit surplus appears to be too large for it to be explained by hedging against carbon risk at least for some firms, because it likely exceeds firms' uncertainty about their future emissions.

I provide no conclusive proof of market power being exerted, and such a proof will likely never exist because firm choices are driven by expectations that are not observable. There may be other explanations for accumulating an allowance surplus than strategic price manipulation. For example, firms may have speculated that prices would increase towards the end of the phase, expecting a profit from sales at the very end, but this raises the question of why no firm bet on a permit price decrease, especially considering the two rounds of emissions that revealed the market to be overall long. Firms could also have simply erred in the quantity of permits they chose to hold, or they might have wrongly assumed that they could bank Phase I permits into the second phase. These explanations seem rather unlikely in the context of large firms that are familiar with trading commodities and rely on precise market predictions for their daily operations. More generally, it seems difficult to reconcile firms' over-purchasing of allowances with the idea of a perfectly competitive market where fully 
informed agents optimize their permit holdings according to theory.

My results suggest that firms may have successfully manipulated the allowance price in their favor during the first two years of Phase I. On the other hand, it seems unlikely that allowance price manipulation can persist in the long run. In a more mature market, one would expect the lack of market power by any single firm as evidenced by the HHI to make price manipulation contingent on collusion, which may be difficult to sustain. Also, since electricity firms no longer receive a free allocation since the beginning of Phase III, the incentive to increase the allowance price should be greatly reduced for all firms, and exchanged for an incentive to decrease it for firms with an above-average emission intensity. This misalignment of firms' incentives makes collusion even less likely.

I conclude that market power in permit markets is an issue that is policy relevant, and especially so in new emission markets. Such markets are being set up in various countries, e.g. in Australia, New Zealand and South Korea, and regulatory authorities should be cautious about large firms' incentive to manipulate prices. In particular, allocating firms most of their needed permits for free is most likely the wrong policy in terms of market efficiency.

\section{References}

Bohringer, Christoph and Andreas Lange (2005) "On the Design of Optimal Grandfathering Schemes for Emission Allowances.," European Economic Review, Vol. 49, No. 8, pp. 2041 2055.

Brown-Kruse, Jamie, Steven R. Elliot, and Rob Godby (1995) "Strategic Manipulation of Pollution Permit Markets: An Experimental Approach."

Cetin, Umut and Michel Verschuere (2009) "Pricing and Hedging in Carbon Emissions Markets.," International Journal of Theoretical and Applied Finance, Vol. 12, No. 7, pp. 949 967.

Chesney, Marc and Luca Taschini (2012) “The Endogenous Price Dynamics of Emission Al- 
lowances and an Application to CO2 Option Pricing.," Applied Mathematical Finance, Vol. 19, No. 5-6, pp. $447-475$.

Convery, Frank J (2009) "Origins and development of the EU ETS," Environmental and Resource Economics, Vol. 43, No. 3, pp. 391-412.

Disegni Eshel, Dafna M. (2005) "Optimal Allocation of Tradable Pollution Rights and Market Structures.," Journal of Regulatory Economics, Vol. 28, No. 2, pp. 205 - 223.

Dixit, Avinash K. and Robert S. Pindyck (1994) Investment under uncertainty: Princeton university press.

EEA, (2006) Application of the emissions trading directive by EU Member States: European Environment Agency Technical report No 2/2006.

European Commission, (2004) Guidelines on the assessment of horizontal mergers under the Council Regulation on the control of concentrations between undertakings: Official Journal of the European Union, 2004/C 31/03.

Fell, Harrison, Beat Hintermann, and Herman Vollebergh (2013) "Estimation of carbon cost pass-through in electricity markets." CESifo Working Paper No. 4367.

Godby, Robert (2002) “Market Power in Laboratory Emission Permit Markets.," Environmental and Resource Economics, Vol. 23, No. 3, pp. 279 - 318.

Hahn, Robert W. (1984) “Market Power and Transferable Property Rights.," Quarterly Journal of Economics, Vol. 99, No. 4, pp. 753 - 765.

Harstad, Bård and Gunnar S Eskeland (2010) "Trading for the future: Signaling in permit markets," Journal of Public Economics, Vol. 94, No. 9, pp. 749-760.

Hintermann, Beat (2010) "Allowance Price Drivers in the First Phase of the EU ETS.," Journal of Environmental Economics and Management, Vol. 59, No. 1, pp. 43 - 56.

(2011) "Market Power, Permit Allocation and Efficiency in Emission Permit Markets.," Environmental and Resource Economics, Vol. 49, No. 3, pp. 327 - 349. 
(2012) "Pricing Emission Permits in the Absence of Abatement.," Energy Economics, Vol. 34, No. 5, pp. 1329 - 1340 .

Jaraite, Jurate, Frank Convery, and Corrado Di Maria (2010) "Transaction Costs for Firms in the EU ETS: Lessons from Ireland.," Climate Policy, Vol. 10, No. 2, pp. 190 - 215.

Krattenmaker, Thomas G. and Steven C. Salop (1986) "Competition and Cooperation in the Market for Exclusionary Rights.," American Economic Review, Vol. 76, No. 2, pp. 109 - 113.

Liski, Matti and Juan-Pablo Montero (2005) "A Note on Market Power in an Emission Permits Market with Banking.," Environmental and Resource Economics, Vol. 31, No. 2, pp. 159 173.

(2011) "Market Power in an Exhaustible Resource Market: The Case of Storable Pollution Permits.," Economic Journal, Vol. 121, No. 551, pp. 116 - 144.

Mansanet-Bataller, Maria, Angel Pardo, and Enric Valor (2007) "CO2 Prices, Energy and Weather.," Energy Journal, Vol. 28, No. 3, pp. 73 - 92.

Misiolek, Walter S. and Harold W. Elder (1989) "Exclusionary Manipulation of Markets for Pollution Rights.," Journal of Environmental Economics and Management, Vol. 16, No. 2, pp. $156-166$.

Muller, R. Andrew and Stuart Mestelman (1998) "What Have We Learned from Emmissions Trading Experiments?.," Managerial and Decision Economics, Vol. 19, No. 4-5, pp. 225 238.

Neuhoff, Karsten, Kim Keats Martinez, and Misato Sato (2006) "Allocation, Incentives and Distortions: The Impact of EU ETS Emissions Allowance Allocations to the Electricity Sector.," Climate Policy, Vol. 6, No. 1, pp. 73 - 91.

Oberndorfer, Ulrich (2009) "EU Emission Allowances and the Stock Market: Evidence from the Electricity Industry.," Ecological Economics, Vol. 68, No. 4, pp. 1116 - 1126.

Salop, Steven C. and David T. Scheffman (1983) "Raising Rivals' Costs.," American Economic Review, Vol. 73, No. 2, pp. $267-271$. 
Sartzetakis, Eftichios Sophocles (1997) "Raising Rivals' Costs Strategies via Emission Permits Markets.," Review of Industrial Organization, Vol. 12, No. 5-6, pp. 751 - 765.

Seifert, Jan, Marliese Uhrig-Homburg, and Michael Wagner (2008) "Dynamic Behavior of CO2 Spot Prices.," Journal of Environmental Economics and Management, Vol. 56, No. 2, pp. $180-194$.

Sijm, Jos, Karsten Neuhoff, and Yihsu Chen (2006) " $\mathrm{CO}_{2}$ Cost Pass-Through and Windfall Profits in the Power Sector.," Climate Policy, Vol. 6, No. 1, pp. 49 - 72.

Sinn, Hans-Werner and Ulrich Schmoltzi (1981) "Eigentumsrechte, Kompensationsregeln und Marktmacht-Anmerkungen zum 'Coase Theorem'. (Property Rights, Compensation Rules and Market Power-Comments on the 'Coase Theorem.' With English summary.).," Jahrbucher fur Nationalokonomie und Statistik, Vol. 196, No. 2, pp. 97 - 117.

US Department of Justice, (2010) Horizontal merger guidelines: Issued August 19.

Zhao, Jinhua (2003) "Irreversible abatement investment under cost uncertainties: tradable emission permits and emissions charges," Journal of Public Economics, Vol. 87, No. 12, pp. 2765-2789. 